\title{
Opinions and attitudes of parturients, midwives, and obstetricians about Caesarean section in the provinces of Podkarpackie, Poland, and Ivano-Frankivsk, Ukraine
}

\author{
Joanna Skręt-Magierło1,2, Edyta Barnaś3 ${ }^{3}$, Sławomir Januszek², Teresa Zmysło', \\ Andrzej Skręt ${ }^{4}$, Elżbieta Kraśnianin ${ }^{4}$, Nataliya Henryk ${ }^{4}$, Oksana Makarchuk ${ }^{4}$, Iryna Basiuga ${ }^{4}$, \\ Omelyan Kwartsyany ${ }^{4}$ \\ 1 Institute of Obstetrics and Emergency Medicine, University of Rzeszow, Poland \\ ${ }^{2}$ Clinical Department of Obstetrics and Gynecology, Rzeszow State Hospital, Rzeszow, Poland \\ ${ }^{3}$ The Psychoterapy \& Counseling Center, Warrington, UK \\ ${ }^{4}$ Chair of Obstetrics and Gynecology, Medical University of Iwano-Frankowsk, Ukraine
}

Skręt-Magierło J, Barnaś E, S Januszek, Zmysło T, Skręt A, Kraśnianin E, Henryk N, Makarchuk O, Basiuga I, Kwartsyany O. Opinions and attitudes of parturients, midwives, and obstetricians about Caesarean section in the provinces of Podkarpackie, Poland, and Ivano-Frankivsk, Ukraine. Ann Agric Environ Med. 2016; 23(1): 157-162. doi: 10.5604/12321966.1196873

\begin{abstract}
I Abstract
Introduction and objective. Present the opinions of parturients, midwives, and obstetricians concerning CS in the provinces of Podkarpackie (Poland) and Ivano-Frankivsk (Ukraine).

Material and methods. An anonymous questionnaire for parturients $(n=1,295)$, midwives $(n=47)$ and obstetricians $(n=78)$, assessing demographics, knowledge and attitudes concerning CS, was distributed in 13 hospitals. In addition to measured anxiety among parturients, we also used the State-Trait Anxiety Inventory (STAI).

Results. Differences between the subgroups concerned respondents' ages and place of residence $(p=0.0000)$. Parturients from Poland more often accepted the possibility of vaginal delivery after previous $\operatorname{CS}(p=0.0000)$, they more often believed that free access to epidural analgesia and the presence of a chosen partner in the delivery room would decrease the CS rate $(p=0.0000)$. Polish midwives more rarely accept the idea of $C S$ on maternal request $(p=0.0012)$ and were convinced that free access to epidural analgesia could decrease the rate of CS $(p=0.0479)$. In Poland parturients more often accepted CS on maternal request than obstetricians and midwives $(p=0.0000)$. In Ukrainian population midwives and obstetricians more often accepted possibility of natural delivery after previous CS $(p=0.0010)$. According connected with delivery in Poland parturients returned lower scores on the A-State scale $(p=0.0000)$, but higher scores on the A-Trait scale $(p=0.0067)$.

Conclusions. There are some differences in Polish and Ukrainian obstetricians, midwives and parturients in respect of: vaginal delivery after CS, - epidural analgesia, - CS on request, - anxiety connected with labour. The above may to some extend explain the difference in Cs rate in two countries.
\end{abstract}

\section{Key word}

cesarean section, opinions, anxiety

\section{INTRODUCTION}

Recent years have brought an increasing number of Caesarean section (CS) procedures, both in Poland and worldwide. The World Health Organization (WHO) reported in 2008 that between $2000-2006$ the highest CS rates were found in the Dominican Republic (31\%), Portugal (30\%), Columbia (27\%), Malta (25\%), USA (23\%), Hungary (23\%), and Germany (22\%). The general rate of CS shows an upward trend around the world, e.g. Taiwan, Australia (up to 30\%), and in private hospitals in Chile where it is a high as $60 \%[1$, $2,3,4]$. This epidemiological situation results from progress in medicine as well as the new concept of CS performed 'on maternal request'. The reasons for CS on maternal request are different, but the most common are previous traumatic birth experience, women's fear of giving birth, and concerns

Address for correspondence: Joanna Skręt-Magierło, Szopena 2, 35-055 Rzeszów Poland

E-mail: joannaskret@wp.pl

Received: 29 August 2013; accepted: 18 February 2014 about the safety of the baby. Other risk factors for increased fear and anxiety before giving birth include single status or dissatisfaction with a partnership, nulliparity, and lack of support $[5,6,7,8]$.

The CS rate has also increased in Poland: in 1999 it was $18.2 \%$, whereas in 2008 it reached 30.5\% [9]. The data concerning 2009-2011 from the Polish province of Podkarpackie indicated a similar trend, with a CS rate close to $40 \%$. There are no official records about numbers of CS on maternal request. However, data from the nearby Ivano-Frankivsk province in the Ukraine, which is only $200 \mathrm{~km}$ from Podkarpackie province, indicate that the rate of CS has not changed there since 2000, and remains at $17 \%$. The two regions are of similar area (Podkarpackie $17,846 \mathrm{~km}^{2}$ vs. Ivano-Frankivsk $-13,900 \mathrm{~km}^{2}$ ); population of Podkarpackie - 2,103,505, Ivano-Frankivsk - 1,388,000. The nature of the maternity healthcare system in both regions is similar: regionalizing level III perinatal care, possibility of attending antenatal classes during pregnancy, births take place in public hospitals, absence of maternity homes or home 
births. There are no official data on the scale of anxiety among parturients in both regions. When analyzing differences and similarities regarding the functioning of the system in the two provinces, it was considered of interest to investigate factors determining the significant discrepancy in CS rates between the Podkarpackie and Ivano- Frankivsk provinces.

\section{OBJECTIVE}

The aim of the study was to present the opinions and attitudes of parturients, midwives, and obstetricians about CS in the provinces of Podkarpackie (Poland) and Ivano-Frankivsk (Ukraine). An additional aim was to assess the relationship between anxiety of parturients and their attitudes to CS.

\section{MATERIALS AND METHOD}

The study sample comprised 1,420 respondents who consented to participate in the study (1,295 parturients, 47 midwives, and 78 obstetricians), invited to participate in the survey in 13 hospitals in Podkarpackie and IvanoFrankivsk provinces. The inclusion criteria were: parturients above 36 weeks gestation, aged 18 years or older; midwives and obstetricians working at the department of obstetrics where the women presented for delivery.

Data were collected using a data collection form prepared in line with the information found in the literature $[1,7]$. Before the main study was conducted, a pilot study was carried out on 50 women who were not included in the main study. Based on the results of the pilot study, the questionnaire was modified for comprehensibility and usability. In order to describe the relationship between fear of parturients and their attitude to CS, the State-Trait Anxiety Inventory, Polish and Russian Ukrainian versions, were used. This instrument has two scales, consisting of two sets of 20 statements, each measuring a different dimension of anxiety. The first set of statements (A-State) elicits how the respondent feels at the moment, while the second set of statements (A-Trait) elicits how the respondents feel generally [10]. In using the STAI questionnaire, the parturients were asked to describe how they feel at the present time thinking about delivery.

The study was approved by the Ethics Committee, No. 6/07/2010. The data were collected between August 2010 December 2011. Data were coded and entered into a database, and then exported to the STATISTICA 10.0 software for analysis.

\section{RESULTS}

Table 1 presents a general profile of the study group from the Ukraine $(\mathrm{N}=351)$ and Poland $(\mathrm{N}=942)$. Differences between the subgroups concerned respondents' ages (the pregnant women in Ukraine were younger than the women in Poland - 26.1 vs. 29.0), and place of residence (the majority of the Polish population (57.2\%) lived in rural areas, whereas the largest number of Ukrainian respondents (40.4\%) lived in cities). Other socio-demographic parameters were similar in both subgroups.

On analyzing the opinions regarding CS presented by parturients, it was found that respondents from both
Table 1. General profile of parturients from Poland and Ukraine

\begin{tabular}{|c|c|c|c|}
\hline Variables & Poland $(\mathrm{N}=944)$ & Ukraine $(\mathrm{N}=351)$ & $\mathrm{p}$ \\
\hline Age & $29.0 \pm 6,1$ & $26.1 \pm 4.8$ & $\left(0.0000^{* * *}\right)$ \\
\hline \multicolumn{4}{|c|}{ Place of residence } \\
\hline rural & $531(57.2 \%)$ & $93(28.3 \%)$ & $\left(0.0000^{* * *}\right)$ \\
\hline town & $229(24.7 \%)$ & $103(31.3 \%)$ & \\
\hline city & $169(18.2 \%)$ & $133(40.4 \%)$ & \\
\hline \multicolumn{4}{|c|}{ Education } \\
\hline primary & $32(3.4 \%)$ & $8(2.5 \%)$ & $(0.853)$ \\
\hline vocational & $110(11.7 \%)$ & $44(13.8 \%)$ & \\
\hline high school & $424(45.3 \%)$ & $79(24.8 \%)$ & \\
\hline college & $90(9.6 \%)$ & $155(48.6 \%)$ & \\
\hline university & $281(30.0 \%)$ & $33(10.3 \%)$ & \\
\hline \multicolumn{4}{|c|}{ Marital status } \\
\hline single & $83(8.8 \%)$ & $15(4.6 \%)$ & $(0.067)$ \\
\hline married & $833(88.6 \%)$ & $293(90.2 \%)$ & \\
\hline divorced & $18(1.9 \%)$ & $15(4.6 \%)$ & \\
\hline widow & $6(0.6 \%)$ & $2(0.6 \%)$ & \\
\hline \multicolumn{4}{|c|}{ Parity } \\
\hline primiparous & 447 (47.3\%.) & $163(46.4 \%)$ & $(0.053)$ \\
\hline \multicolumn{4}{|l|}{ multiparous: } \\
\hline • natural delivery & 354 (37.5\%) & $163(46.4 \%)$ & \\
\hline - previous Caesarean section & $143(15.2 \%)$ & $25(7.2 \%)$ & \\
\hline
\end{tabular}

$p<0.05^{*} p<0.01^{* *} p<0.001^{* * *}$

subgroups approved of CS on maternal request $(64.5 \%$ vs. $58.4 \%$; $\mathrm{p}=0.1228)$. The possibility of natural delivery after previous CS was stressed more clearly among Polish respondents $(83.2 \%$ vs. $61.0 \% ; \mathrm{p}=0.0000)$. This group of respondents also believed that free access to epidural analgesia would significantly decrease the rate of CS $(84.4 \%$ vs. $62.7 \% ; \mathrm{p}=0.0000$ ). According to $28.7 \%$ of Polish women participating in the study the optimal CS rate was $21-30 \%$. In the Ukrainian subgroup, $41.0 \%$ of parturients estimated the optimal rate at a level of $11-20 \%(\mathrm{p}=0.0000)$. Next, the opinions about CS reported by midwives was analyzed. A greater number of respondents from the Ukraine approved of CS on maternal request $(60.0 \%$ vs. $14.8 \%$; $p=0.0012)$. Polish midwives were convinced that free access to epidural analgesia could decrease the rate of CS (88.9\% vs. $65.0 \%$; $\mathrm{p}=0.0479)$. The Polish group of doctors believed that natural delivery was possible after CS in the past (100\% vs. $89.7 \%$; $\mathrm{p}=0.0400)$. According to the Ukrainian obstetricians the optimal CS rate was $11-20 \%$ (56.4\% vs. $23.7 \%$; $\mathrm{p}=0.0000)$ (Tab. 2).

Analysis of opinions about CS presented by the Polish population showed that there were marked differences concerning approval of CS on maternal request. Parturients were the most numerous subgroup accepting this type of delivery ( $64.5 \%$ vs. $14.8 \%$ vs. $35.9 \%$; $\mathrm{p}=0.0000)$. Vaginal birth was seen as significantly more hazardous by parturients than by midwives or obstetricians ( 3.3 vs. 2.0 vs. 2.2 ; $p=0.0000$ ). Analysis of answers given by the Ukrainian respondents indicates differences regarding selected items: possibility of natural delivery after previous CS - the largest percentage was recorded among midwives and obstetricians $(90.0 \%$ vs. 89.7\%; $\mathrm{p}=0.0010$ ). As far as the risk of a vaginal birth was concerned, midwives and parturients assessed it as high, 
Table 2. Opinions about CS presented by respondents in Poland and Ukraine

\begin{tabular}{|c|c|c|c|c|c|c|c|c|c|}
\hline \multirow[b]{2}{*}{ Possible answers } & \multicolumn{3}{|c|}{ Parturients } & \multicolumn{3}{|c|}{ Midwives } & \multicolumn{3}{|c|}{ Obstetricans } \\
\hline & $\begin{array}{l}\text { Poland } \\
(\mathrm{N}=944)\end{array}$ & $\begin{array}{l}\text { Ukraine } \\
(\mathrm{N}=351)\end{array}$ & $\mathrm{p}$ & $\begin{array}{l}\text { Poland } \\
(\mathrm{N}=27)\end{array}$ & $\begin{array}{l}\text { Ukraine } \\
(\mathrm{N}=20)\end{array}$ & $\mathrm{p}$ & $\begin{array}{l}\text { Poland } \\
(\mathrm{N}=39)\end{array}$ & $\begin{array}{l}\text { Ukraine } \\
(\mathrm{N}=39)\end{array}$ & $\mathrm{p}$ \\
\hline Vaginal delivery after previous CS-yes & $83.2 \%$ & $61.0 \%$ & $0.0000^{* * *}$ & $92.6 \%$ & $90.0 \%$ & 0.7528 & $100.0 \%$ & $89.7 \%$ & $0.0400^{*}$ \\
\hline Free access to epidural analgesia would decrease the CS rate-Yes & $84.4 \%$ & $62.7 \%$ & $0.0000 * * *$ & $88.9 \%$ & $65.0 \%$ & $0.0479^{*}$ & $84.6 \%$ & $66.7 \%$ & 0.0648 \\
\hline $\begin{array}{l}\text { The presence of a chosen partner in the delivery room would decrease } \\
\text { the CS rate-Yes }\end{array}$ & $74.8 \%$ & $61.8 \%$ & $0.0000^{* * *}$ & $74.1 \%$ & $60.0 \%$ & 0.3061 & $71.8 \%$ & $82.1 \%$ & 0.2824 \\
\hline \multicolumn{3}{|l|}{ Optimal CS rate } & \multirow{6}{*}{$0.0000^{* * *}$} & & & \multirow{6}{*}{0.8731} & & & \multirow{6}{*}{$0.0000^{* * *}$} \\
\hline Up to $5 \%$ & $0.5 \%$ & $3.7 \%$ & & $7.4 \%$ & $0.0 \%$ & & $2.6 \%$ & $2.6 \%$ & \\
\hline $5 \%-10 \%$ & $7.3 \%$ & $11.1 \%$ & & $14.8 \%$ & $5.0 \%$ & & $7.9 \%$ & $28.2 \%$ & \\
\hline $11 \%-20 \%$ & $25.7 \%$ & $41.0 \%$ & & $29.6 \%$ & $50.0 \%$ & & $23.7 \%$ & $56.4 \%$ & \\
\hline $31 \%-40 \%$ & $23.8 \%$ & $8.3 \%$ & & $7.4 \%$ & $10.0 \%$ & & $13.2 \%$ & $2.6 \%$ & \\
\hline$>40 \%$ & $12.0 \%$ & $15.1 \%$ & & $14.8 \%$ & 5.0 & & $18.4 \%$ & $0.0 \%$ & \\
\hline Evaluation of risk related to CS using the VAS scale & $4.8 \pm 2.2$ & $4.6 \pm 2.4$ & 0.0530 & $5.4 \pm 2.2$ & $5.6 \pm 3.1$ & 0.6777 & $4.9 \pm 2.5$ & $5.0 \pm 3.0$ & 0.6404 \\
\hline Evaluation of risk related to vaginal delivery using the VAS scale & $3.3 \pm 1.8$ & $3.8 \pm 2.3$ & $0.0007^{* * *}$ & $2.0 \pm 1.1$ & $4.0 \pm 2.6$ & $0.0061^{* *}$ & $2.2 \pm 1.3$ & $2.6 \pm 2.0$ & 0.7580 \\
\hline
\end{tabular}

$p<0.05^{*} \quad p<0.01^{* *} \quad p<0.001^{* * *}$

Table 3. Attitude of respondents towards CS in Polish and Ukrainian population

\begin{tabular}{|c|c|c|c|c|c|c|c|c|}
\hline \multirow[b]{2}{*}{ Possible answers } & \multicolumn{4}{|c|}{ Polish population } & \multicolumn{4}{|c|}{ Ukrainian population } \\
\hline & $\begin{array}{l}\text { Parturients } \\
(\mathrm{N}=944)\end{array}$ & $\begin{array}{l}\text { Midwives } \\
(\mathrm{N}=27)\end{array}$ & $\begin{array}{l}\text { Obstetricans } \\
\quad(\mathrm{N}=39)\end{array}$ & $\mathrm{p}$ & $\begin{array}{l}\text { Parturients } \\
(\mathrm{N}=351)\end{array}$ & $\begin{array}{l}\text { Midwives } \\
(\mathrm{N}=20)\end{array}$ & $\begin{array}{l}\text { Obstetricans } \\
\qquad(\mathrm{N}=39)\end{array}$ & $\mathrm{p}$ \\
\hline $\begin{array}{l}\text { Approval of CS on maternal request without medical indications- } \\
\text { yes }\end{array}$ & $64.5 \%$ & $14.8 \%$ & $35.9 \%$ & $0.0000^{* * *}$ & $58.4 \%$ & $60.0 \%$ & $38.5 \%$ & 0.1419 \\
\hline Vaginal delivery after previous CS-yes & $83.2 \%$ & $92.6 \%$ & $100.0 \%$ & 0.0495 & $61.0 \%$ & $90.0 \%$ & $89.7 \%$ & $0.0010^{* * *}$ \\
\hline Free access to epidural analgesia would decrease the CS rate-yes & $84.4 \%$ & $88.9 \%$ & $84.6 \%$ & 0.8572 & $62.7 \%$ & $65.0 \%$ & $66.7 \%$ & 0.9087 \\
\hline Psychoprophylaxis would decrease the CS rate-yes & $74.0 \%$ & $77.8 \%$ & $87.2 \%$ & 0.4400 & $78.1 \%$ & $95.0 \%$ & $92.3 \%$ & 0.1132 \\
\hline $\begin{array}{l}\text { The presence of a chosen partner in the delivery room would } \\
\text { decrease the CS rate-yes }\end{array}$ & $74.8 \%$ & $74.1 \%$ & $71.8 \%$ & 0.9190 & $62.1 \%$ & $60.0 \%$ & $82.1 \%$ & 0.1722 \\
\hline \multicolumn{4}{|l|}{ Optimal CS rate } & \multirow{6}{*}{$0.0083^{*}$} & & & & \multirow{6}{*}{$0.0491^{*}$} \\
\hline Up to $5 \%$ & $0.5 \%$ & $7.4 \%$ & $2.6 \%$ & & $3.7 \%$ & $0.0 \%$ & $2.6 \%$ & \\
\hline $5 \%-10 \%$ & $7.3 \%$ & $14.8 \%$ & $7.9 \%$ & & $11.1 \%$ & $5.0 \%$ & $28.2 \%$ & \\
\hline $21 \%-30 \%$ & $28.7 \%$ & $25.9 \%$ & $34.2 \%$ & & $30.2 \%$ & $30.0 \%$ & $10.3 \%$ & \\
\hline $31 \%-40 \%$ & $23.8 \%$ & $7.4 \%$ & $13.2 \%$ & & $8.3 \%$ & $10.0 \%$ & $2.6 \%$ & \\
\hline$>40 \%$ & $12.0 \%$ & $14.8 \%$ & $18.4 \%$ & & $5.1 \%$ & $5.0 \%$ & $0.0 \%$ & \\
\hline Evaluation of risk related to CS using the VAS scale & $4.8 \pm 2.2$ & $5.4 \pm 2.2$ & $4.9 \pm 2.5$ & 0.4588 & & & & 0.3019 \\
\hline Evaluation of risk related to vaginal delivery using the VAS scale & $3.3 \pm 1.8$ & $2.0 \pm 1.1$ & $2.2 \pm 1.3$ & $0.0000^{* * *}$ & & & & $0.0013^{* *}$ \\
\hline
\end{tabular}

$p<0.05^{*} \quad p<0.01^{* *} \quad p<0.001^{* * *}$

whereas obstetricians believed it was lower (3.8 vs. 4.0 vs. 2.6; $\mathrm{p}=0.0013$ ) (Tab. 3).

The level of anxiety was different between the two populations. The Polish population returned lower scores on the A-State scale ( $41.5 \pm 7.8$ vs. $43.6 \pm 9.2 ; \mathrm{p}=0.0000)$, but higher scores on the A-Trait scale ( $47.6 \pm 4.5$ vs. $45.0 \pm 7.9 ; \mathrm{p}=0.0067)$. The knowledge of parturients about CS (on maternal request, the possibility of vaginal birth after previous CS, fear of women as indications for CS) significantly affected the level of A-State anxiety in both populations - it was clearly lower in the Polish population ( $\mathrm{p}=0.0000)$ (Tab. 4).

\section{DISCUSSION}

This is a pioneer study since there are no other reports based on similar methodology in the available literature. It should be emphasized that the selection of respondents was random and two inhomogeneous subgroups of parturients were created. These groups were not representative for either the Polish or Ukrainian populations as a whole. The respondents differed from each other in terms of the parameters of age and the place of residence. No statistically significant difference was found as far as approval of the CS on maternal request was concerned. The majority of parturients from both national subgroups accepted this solution (64.5\% vs. 
Table 4. Mean scores and correlation between opinion concerning CS from parturients in both groups and A-State anxiety

\begin{tabular}{|c|c|c|c|c|c|c|c|}
\hline & \multicolumn{3}{|c|}{ Poland $(\mathrm{N}=944)$} & \multicolumn{3}{|c|}{ Ukraine (N=351) } & \multirow[b]{2}{*}{$p$} \\
\hline & $\bar{x}$ & Me & $s$ & $\bar{x}$ & Me & $s$ & \\
\hline A-STATE & 41.5 & 41.0 & 7.8 & 47.6 & 47.0 & 4.5 & $0.0000^{* * *}$ \\
\hline T-TRAIT & 43.6 & 42.0 & 9.2 & 45.0 & 45.0 & 7.9 & $0.0067^{* *}$ \\
\hline \multicolumn{4}{|c|}{ Possible answers } & \multicolumn{2}{|c|}{$\begin{array}{l}\text { A-State } \\
\text { (Poland) }\end{array}$} & $\begin{array}{l}\text { A-State } \\
\text { (Ukraine) }\end{array}$ & $\mathrm{p}$ \\
\hline
\end{tabular}

Approval of CS on maternal request

without medical indications

$\begin{array}{llll}\text { yes } & 43.6 \pm 6.3 & 47.9 \pm 4.6 & \left(0.0000^{* * *}\right)\end{array}$

Vaginal delivery after previous CS

\begin{tabular}{llll} 
yes & $39.6 \pm 1.8$ & $47.5 \pm 4.5$ & $\left(0.0000^{* * *}\right)$ \\
\hline
\end{tabular}

Anxiety behaviour indication for CS

$\begin{array}{llll}\text { yes } & 40.1 \pm 7.1 & 47.5 \pm 4.3 & \left(0.0000^{* * *}\right)\end{array}$

The presence of a chosen partner in the

delivery room would decrease the CS rate

\begin{tabular}{llll} 
yes & $39.1 \pm 4.3$ & $47.0 \pm 4.3$ & $\left(0.0000^{* * *}\right)$ \\
\hline
\end{tabular}

$p<0.05^{*} \quad p<0.01^{* *} \quad p<0.001^{* * *}$

58.4\%; $\mathrm{p}=0.1228)$. These results confirm findings presented by Pevzner et al., who showed that more than $80 \%$ of a group of pregnant women $(n=833)$ believed that a woman should have the right to decide about the delivery and that the option of CS on maternal request should be available. However, only $6.1 \%$ considered this type of delivery for themselves [11]. Researchers from Sweden $(n=1066)$ published opposite outcomes. They reported that two out of three respondents were convinced that the decision about the CS should be made by obstetricians based on medical indications. Only one-third of the group stated that this was an autonomous decision of a woman, who had every right to make it on her own. These findings correlated with low levels of trust in the health care system, younger age, and being childless [1]

In the presented study, parturients assessed the risk related to vaginal delivery on a 10-point VAS scale and returned the following scores: $3.3 \pm 1.8$ vs. $3.8 \pm 2.3$ points $(\mathrm{p}=0.0007)$. Dursun et al. reported that only $25 \%$ of their study group, which included 400 women aged $32 \pm 10.2$, would have chosen CS in order to avoid lowering of the womb and incontinence, whereas half of the group would prefer that type of delivery to avoid labour pain and minimize risk to the child. It is interesting that $89 \%$ of the same group of respondents believed vaginal birth to be the natural way of delivering a child and declared they wanted give birth naturally [5]. Chingbu et al. showed that the rate of CS on maternal request in Nigeria was $4.4 \%$, and that this surgical intervention was performed in the case of older women and those who had undergone fertility treatment. The great majority of them would prefer to have a natural delivery in the future [12].

Distinct disproportions were observed in the currentr study when analyzing the opinions presented by particular groups of respondents, i.e. parturients, midwives and obstetricians from Poland and the Ukraine. It was observed that the Ukrainian population tended to approve of CS on demand (parturients and midwives). However, this trend did not transfer objectively to the rate of CS $(17 \%$ of all births) when compared with the data from the Podkarpackie province (close to $40 \%$ of all deliveries). Koken et al. showed that the majority of Turkish women working in the health care system and those with no connection to medicine would prefer to have a vaginal birth. In the studied groups, the percentage of respondents presenting the opinion that CS should be performed on maternal request was $37.8 \%$ and $36.2 \%$, respectively [2].

In the presented study, opinions regarding free access to epidural analgesia as a factor decreasing CS rates received higher scores in the Polish group, particularly among Polish midwives $(p=0.0479)$. Fenwick et al. asked women who consciously decided to have a CS in their first pregnancy about the factors which made them perceive natural birth as a traumatic event, and showed how important the role of medical personnel was in this aspect. The ability to identify these factors and create a strategy of trust and confidence is a condition of good cooperation which allows positive reinforcement of women's competences and ability to decide on a natural birth [6]. Munro et al. examined the influence of childbirth experiences (of respondents and those close to them) and cultural factors in a group of 17 women. They also tried to find out why women wanted to have a CS when there were no medical reasons for it. They concluded that social elements should be taken into account when providing antenatal care, and a wide range of psychoprophylactic interventions should be offered to women going into labour [13]. These findings are consistent with outcomes published by Manusco et al., in which 70 obstetricians were asked if they noticed any significant impact of socio-cultural factors on women's decisions on ways of delivery [14]. According to Kudish et al., women with low socio-economic status, high BMI values, and previous CS comprised a group with greater likelihood of a CS [15]. Duckworth underlined that CS on maternal request is often caused by fear of pain and being unaware of consequences; therefore, it is difficult to estimate the number of conscious and autonomous decisions made by parturients requesting a CS [3]. Weaver et al. showed that the major reason why CS was requested was concern for the child and mother, and both women and obstetricians from the United Kingdom and Ireland presented this opinion [7]. Similar findings were published by Romero et al. (2011), who also noticed that women's fear of childbirth was interpreted by obstetricians as the mother's concern for her child rather than her own wellbeing [16].

In the current study, the lowest scores when assessing risks of vaginal birth were recorded in the Ukrainian population $(\mathrm{p}=0.0013)$. The relative risk of a surgical birth was evaluated similarly in corresponding groups of respondents from Poland. Turner et al. showed that pregnant women could accept a higher risk of vaginal delivery than the obstetricians taking care of them. It is interesting that midwives' opinions were closer to those expressed by women than to those of obstetricians [17]. The presented findings are consistent with those published by Turner et al. The risk of a vaginal birth was assessed in the Ukrainian population at $3.8 \pm 2.3$ and $4.0 \pm 2.6$ by women and midwives, respectively $(\mathrm{p}=0.0013)$. The scores recorded in the Polish population were lower: $3.3 \pm 1.8$ for parturients and $2.0 \pm 1.1$ for midwives $(\mathrm{p}=0.0000)$.

The presnted results show that $40 \%$ of obstetricians (no significant differences between the two populations; $\mathrm{p}=0.8148$ ) approved of CS on maternal request without medical indications. Similar data were published by Habiby et al., who asked 1,530 doctors from eight European countries if they approved of CS on demand. There was general acceptance; however, the percentages of obstetricians who believed that women had a right to choose CS differed 
between particular countries. The lowest scores were found in Spain (15\%), France (19\%), and Holland (22\%), and the highest scores in Germany (75\%) and the United Kingdom (79\%) [18].

Yazdizadeh et al. attempted to recognize factors increasing the rate of CS through analysis of the epidemiological situation in Iran in various fields related to management in public and private health care institutions. As a result, financial and economic barriers were identified on both micro- and macroscales, e.g. communication between obstetricians, midwives, insufficient number of medical personnel, lack of innovative models focusing on minimizing stress during a vaginal birth. The authors concluded that complex multidisciplinary and multilevel interventions are needed since the diagnosis of the current condition is only a starting point for systemic changes [4]. Also, Karlström et al. in Sweden saw a need for greater consolidation and cooperation between medical groups, i.e. obstetricians and midwives, in order to decrease the rate of CS in Sweden [19].

The level of mean scores for anxiety was different between the two populations: Poland returned lower scores on the A-State scale $(41.5 \pm 7.8$ vs. $43.6 \pm 9.2 ; \mathrm{p}=0.0000)$, but higher scores on the A-Trait scale $(47.6 \pm 4.5$ vs. $45.0 \pm 7.9 ; \mathrm{p}=0.0067)$. Similar data were published by Błaszczak et al., who obtained a higher level of anxiety on the A-State and A-Trait scale $(\mathrm{p}<0.001)$ in Polish 65 parturients before delivery [20]. A higher mean scores for A-State anxiety in a Polish population was reported by Billert $\mathrm{H}$ et al. among 45 parturients who received epidurial analgesia, with $53.9 \pm 11.8$ reporting anxiety not associated with labour pain [21]. Pomorski et al. reported no differences in complication rates between Caesarean section and vaginal delivery patients, the emotional status of a pregnant woman should be considered as an indication for CS [9]. The authors of the current study did not find any other studies examining anxiety in parturients in Poland and the Ukraine.

In the view of Grant et al., the result showing a trait anxiety score of $>40$ was associated with a six-fold increase in postnatal anxiety disorders and depression, while antenatal anxiety state did not predict postnatal anxiety or depressive disorders [10]. Some studies have shown elevated fear and anxiety in the third trimester of pregnancy. Makara- Studzińska et al. suggest that higher self-esteem, good communication in a relationship, and satisfying social support were associated with a lower incidence of anxiety symptoms during pregnancy [22]. This fear, which may be present during the entire course of pregnancy, can complicate labour and finally lead to postpartum depression, a troubled mother-infant relationship and a longitudinal impact on infant mental development $[23,24]$. Alipour et al. showed that antenatal state anxiety at 38 weeks correlated with fear of childbirth $(\mathrm{p}=0.51)$ and postpartum depression $(\mathrm{p}=0.007)$ [25]. In the presented study, the knowledge of parturients about CS (on maternal request, the possibility of vaginal birth after previous CS, fear of women as indications for CS) significantly affected the level of A-State anxiety in both populations, which was clearly lower in the Polish population $(\mathrm{p}=0.0000)$. Similar results can be found in Haines et al., who compared attitudes and beliefs concerning birth in a sample of Australian and Swedish women in mid-pregnancy. The Australian women were less likely than the Swedish to agree that they would like a birth that 'is as pain free as possible', 'is as natural as possible'; they were also less likely to agree that 'if a woman wants to have a Caesarean she should be able to have one under any circumstances' and 'giving birth is a natural process that should not be interfered with unless necessary' [8]. Karlström et al. reported that women who preferred and actually delivered by Caesarean section experienced a fear of childbirth to a higher degree than women with a vaginal birth. In addition, women who had CS on request were not pleased with the decision-making process [19].

\section{CONCLUSIONS}

There are some differences among Polish and Ukrainian obstetricians, midwives and parturients in respect of:

- vaginal delivery after CS;

- epidural analgesia;

- CS on request;

- anxiety connected with labour.

The above, to some extent, may explain the difference in the CS rates in the two countries.

\section{REFERENCES}

1. Högberg U, Lynöe N, Wulff M. Cesarean by choice? Empirical study of public attitudes. Acta Obstet Gynecol Scand. 2008; 87(12): 1301-8.

2. Koken G, Cosar E, Sahin FK, Arioz DT, Duman Z, Aral I. Attitudes towards mode of delivery and cesarean on demand in Turkey. Int J Gynaecol Obstet. 2007; 99(3): 233-5.

3. Duckworth S. Should maternal choice be an indication for cesarean section? Int J Surg. 2008; 6(4): 277-80.

4. Yazdizadeh B, Nedjat S, Mohammad K, Rashidian A, Changizi $\mathrm{N}$, Majdzadeh R. Cesarean section rate in Iran, multidimensional approaches for behavioral change of providers: a qualitative study. BMC Health Serv Res. 2011; 5(11): 159.

5. Dursun P, Yanik FB, Zeyeneloglu HB, Baser E, Kuscu E, Ayhan A. Why women request cesarean section without medical indication? J Matern Fetal Neonatal Med. 2011; 24(9): 1133-7.

6. Fenwick J, Staff L, Gamble J, Creedy DK, Bayes S. Why women request caesarean section in a normal healthy pregnancy? Midwifery. 2010; 26(4): 394-400.

7. Weaver JJ, Statham H, Richards M. Are There "Unnecessary" Cesarean Sections? Perceptions of Women and Obstetricians About Cesarean Sections for Nonclinical Indications. Birth. 2007; 34(1): 32-41.

8. Haines H, Rubertsson C, Pallant JF, Hildingsson I. Womens' attitudes and beliefs of childbirth and association with birth preference: A comparison of a Swedish and an Australian sample in mid-pregnancy. Midwifery. 2012; 28(6): 850-6.

9. Pomorski M, Woytoń R, Woytoń P, Kozłowska J, Zimmer M. Cesarean section versus vaginal delivery - state-of-the-art paper. Ginekol Pol. 2010; 81(5): 347-351.

10. Grant KA, McMahon C, Austin MP. Maternal anxiety during the transition to parenthood: a prospective study. J Affect Disord. 2008; 108(1-2): 101-11.

11. Pevzner L, Preslicka C, Bush MC, Chan K. Women's attitudes regarding mode of delivery and cesarean delivery on maternal request. J Matern Fetal Neonatal Med. 2011; 24(7): 894-9.

12. Chigbu CO, Ezeome IV, Iloabachie GC. Cesarean section on request in a developing country. Int J Gynaecol Obstet. 2007; 96(1): 54-6.

13. Munro S, Kornelsen J, Hutton E. Decision Making in Patient- Initiated Elective Cesarean Delivery: The Influence of Birth Stories. J Midwifery Womens Health. 2009; 54(5): 373-9.

14. Manusco A, De Vivo A, Fanara G, Albiero A, Priolo AM, Giacobbe $A$ et al. Cesarean section on request: are there loco-regional factors influencing maternal choice? An Italian experience. J Obstet Gynaecol. 2008; 28(4): 382-5.

15. Kudish B, Mehta S, Kruger M, Russell E, Sokol RJ. Delivery route preferences of urban women of low socioeconomic status. Int J Gynaecol Obstet. 2010; 111(1): 28-31. 
16. Romero ST, Coulson CC, Galvin SL. Cesarean Delivery on Maternal Request: A Western North Carolina Perspective. Matern Child Health J. 2012; 16(3): 725-34.

17. Turner CE, Young JM, Solomon MJ, Ludlow J, Benness C, Phipps H. Vaginal delivery compared with elective cesarean section: the views of pregnant women and clinicians. BJOG: 2008; 115(12): 1494-502.

18. Habiba M, Kaminski M, Da Frè M, Marsal K, Bleker O, Librero J, et al Cesarean section on request: a comparison of obstetrician's attitudes in eight European countries. BJOG. 2006; 113(6): 647-56.

19. Karlström A, Nystedt A, Hildingsson I. A comparative study of the experience of childbirth between women who preferred and had a caesarean section and women who preferred and had a vaginal birth. Sex Reprod Healthc. 2011; 2(3): 93-9.

20. Błaszczak A, Pilch D, Szamlewska B. Research of anxiety level at women before and after delivery of a baby with the Ch. D Speilberg Questionnaire STAI. Perinatologia, Neonatologia i Ginekologia 2011; 3: $163-8$.
21. Billert H, Gaca M, Mikulska J, Bręborowicz G. Anxiety assessment in parturients requesting epidural analgesia. Ginekol Pol. 2007; 78(7): $532-8$.

22. Makara-Studzińska M, Morylowska-Topolska J, Sygit K, Sygit M, Goździewska M. Socio-demographical and psychosocial determinants of anxiety symptoms in a population of pregnant women in the regions of central and eastern Poland. Ann Agric Environ Med. 2013; 20(1): 195-202.

23. Rouhe H, Salmela-Aro K, Halmesmäki E, Saisto T. Fear of childbirth according to parity, gestational age, and obstetrics history. BJOG. 2009; 116(1): 67-73.

24. Grant KA, McMahon C, Reilly N, Austin MP. Maternal sensitivity moderates the impact of prenatal anxiety disorder on infant mental development. Early HumDev. 2010; 86: 551-6.

25. Alipour Z, Lamyian M, Hajizadeh E. Anxiety and fear of childbirth as predictors of postnatal depression in nulliparous women. Women Birth. 2012; 25(3): 37-43. 